\title{
The power of tax and price
}

\section{Frank J Chaloupka, ${ }^{1}$ John A Tauras ${ }^{2}$}

In this issue, Kostova and colleagues provide the strongest evidence to date on the effectiveness of higher cigarette prices in reducing youth smoking in low- and middle-income countries (LMICs). Their analysis of data from multiple waves of the Global Youth Tobacco Survey (GYTS) conducted in 17 LMICs between 1999 and 2006 shows that increased cigarette prices would lead to significant reductions in both youth smoking prevalence and the number of cigarettes consumed by youth who continue to smoke. Specifically, they estimate that increasing cigarette prices by $10 \%$ would reduce the prevalence of youth smoking by at least $7.4 \%$, while reducing young smokers' cigarette intake by nearly $14 \%$. These findings confirm the findings from the relatively extensive research from high-income countries, as well as the smaller but growing evidence from individual LMICs, which clearly shows that youth smoking responds to price. ${ }^{1}$ Moreover, Kostova and colleagues' estimates add to the evidence that smoking among young people responds more to price than does smoking among adults. Their estimated overall price elasticity of youth smoking of -2.11 is well above the estimates obtained for the price elasticity of adult smoking in LMICs, where most previous estimates fall in the range of -0.2 to $-0.6 .^{1}$ Finally, their findings suggesting that stronger tobacco control policies and programmes, including comprehensive bans on tobacco company marketing, increased countermarketing and wellimplemented restrictions on youth access to tobacco productsNote to, would lead to further reductions in youth tobacco use.

In addition, Kostova and colleagues' use of the GYTS data in combination with the cigarette price data collected regularly by the Economist Intelligence Unit provides a good illustration of the value of global tobacco surveillance efforts. The consistent data collected in the GYTS and the multiple waves collected in the countries they analysed allowed them to

${ }^{1}$ Health Policy Center, University of Illinois, Chicago, Illinois, USA; ${ }^{2}$ Department of Economics, University of Illinois, Chicago, Illinois, USA

Correspondence to Professor Frank J Chaloupka, Department of Economics, University of Illinois, Chicago, Illinois, USA; fjc@uic.edu disentangle the effects of cigarette prices from those of other factors that influence youth smoking. Continued and expanded global tobacco surveillance and monitoring efforts will enable researchers to better evaluate the determinants of tobacco use, strengthening the evidence base for higher taxes, stronger tobacco control policies and increasingly comprehensive tobacco control programmes.

The new evidence provided by Kostova and colleagues reinforces the WHO's Framework Convention on Tobacco Control's call for higher taxes and prices on tobacco products, in part because of their greater effectiveness in reducing tobacco use among young people. ${ }^{2}$ As of mid-August 2011, there were 174 parties to the Convention, representing $87.4 \%$ of the world's population. ${ }^{3}$ Nevertheless, despite the treaty's call for higher taxes, few countries tax tobacco products at the recommended levels. Over a decade ago, the World Bank called for governments committed to curbing the tobacco epidemic to raise taxes on tobacco products so that they accounted for between two-thirds and four-fifths of cigarette prices. $^{4}$ Recently, the WHO provided additional guidance, emphasising the importance of excise taxes on tobacco products given that excises, unlike general sales taxes or value added taxes, differentiate the prices of tobacco products from the prices of other goods and services and, as a result, have a greater impact on tobacco use. In the 'best practices' described in its Technical Manual on Tobacco Tax Administration, the WHO recommends that tobacco excise taxes be set at a level that accounts for $70 \%$ of the retail prices for tobacco products. ${ }^{5}$

Few governments have come close to meeting either target. ${ }^{6}$ Globally, excise taxes and other tobacco-specific taxes accounted for just over $40 \%$ of retail cigarette prices. The share of cigarette prices accounted for by excise taxes is the highest in high-income countries-53.1\% - and falls to $34.6 \%$ and $26.7 \%$ in middle- and low-income countries, respectively. Only 26 countries, representing $8 \%$ of the world's population, have total taxes that account for at least three-fourths of retail cigarette prices, with only a handful of countries meeting
WHO target of excises accounting for $70 \%$ of price. ${ }^{6}$ More disturbing is the relative lack of progress in reaching these goals, with only 11 countries raising taxes sufficiently to meet the $75 \%$ target between 2008 and 2010, while six others that had been at that level fell behind as inflation eroded the share of price accounted for by specific taxes. ${ }^{6}$ Moreover, relatively rapid development in many LMICs coupled with little or no change in tobacco taxes has resulted in cigarettes becoming much more affordable in these countries. ${ }^{7}$ Furthermore, despite the substantial revenues generated by tobacco taxes, few governments dedicate even a small fraction of these revenues to support other tobacco control efforts. ${ }^{6}$

The health and economic consequences of this inaction are enormous. Every day, as many as 100000 young people around the world take up smoking. ${ }^{8}$ Currently, about 6 million people die prematurely each year from diseases caused by their tobacco use; given existing trends, this will rise to 8 million over the next two decades, with the burden increasingly falling on LMICs. ${ }^{6}$ Hundreds of billions of dollars are spent each year to treat the diseases caused by tobacco use, with economies losing hundreds of billions more as tobacco users miss work and die prematurely. Tobacco use constrains economic development and the financial burden and lost income resulting from diseases caused by tobacco use can cause families to fall into poverty. ${ }^{9}$

The compelling new evidence provided by Kostova and colleagues adds to the large and growing global evidence base that clearly demonstrates that governments can effectively combat the tobacco epidemic and the death, disease, poverty and economic costs it causes by raising taxes on cigarettes and other tobacco products.

\section{Competing interests None.}

Provenance and peer review Commissioned; internally peer reviewed.

Tobacco Control 2011;20:391-392.

doi:10.1136/tobaccocontrol-2011-050235

\section{REFERENCES}

1. International Agency for Research on Cancer. IARC Handbooks of Cancer Prevention. Volume 14. Effectiveness of Price and Tax Policies for Control of Tobacco. Lyon, France: International Agency for Research on Cancer. In press.

2. World Health Organization. WHO Framework Convention on Tobacco Control. Geneva: World Health Organization, 2003.

3. Framework Convention Alliance. http://www.fctc. org (accessed 23 Aug 2011).

4. World Bank. Curbing the Epidemic: Governments and the Economics Of Tobacco Control. Washington DC: The World Bank, 1999. 
5. World Health Organization. WHO Technical Manual on Tobacco Tax Administration. Geneva, Switzerland: World Health Organization, 2010.

6. World Health Organization. WHO Report on the Global Tobacco Epidemic, 2011. Geneva: World Health Organization, 2011.
7. Blecher E, van Walbeek C. An Analysis of Cigarette Affordability. Paris: International Union Against Tuberculosis and Lung Disease, 2008.

8. World Health Organization. Smoking Statistics. Manila, Philippines: World Health Organization, Western Pacific Regional Office. http://www.wpro. who.int/media_centre/fact_sheets/fs_20020528.htm (accessed 23 Aug 2011).

9. Esson KM, Leeder SR. The Millennium Development Goals and Tobacco Control: An Opportunity for Global Partnership. Geneva, Switzerland: World Health Organization, 2005.

\section{The Lighter Side}

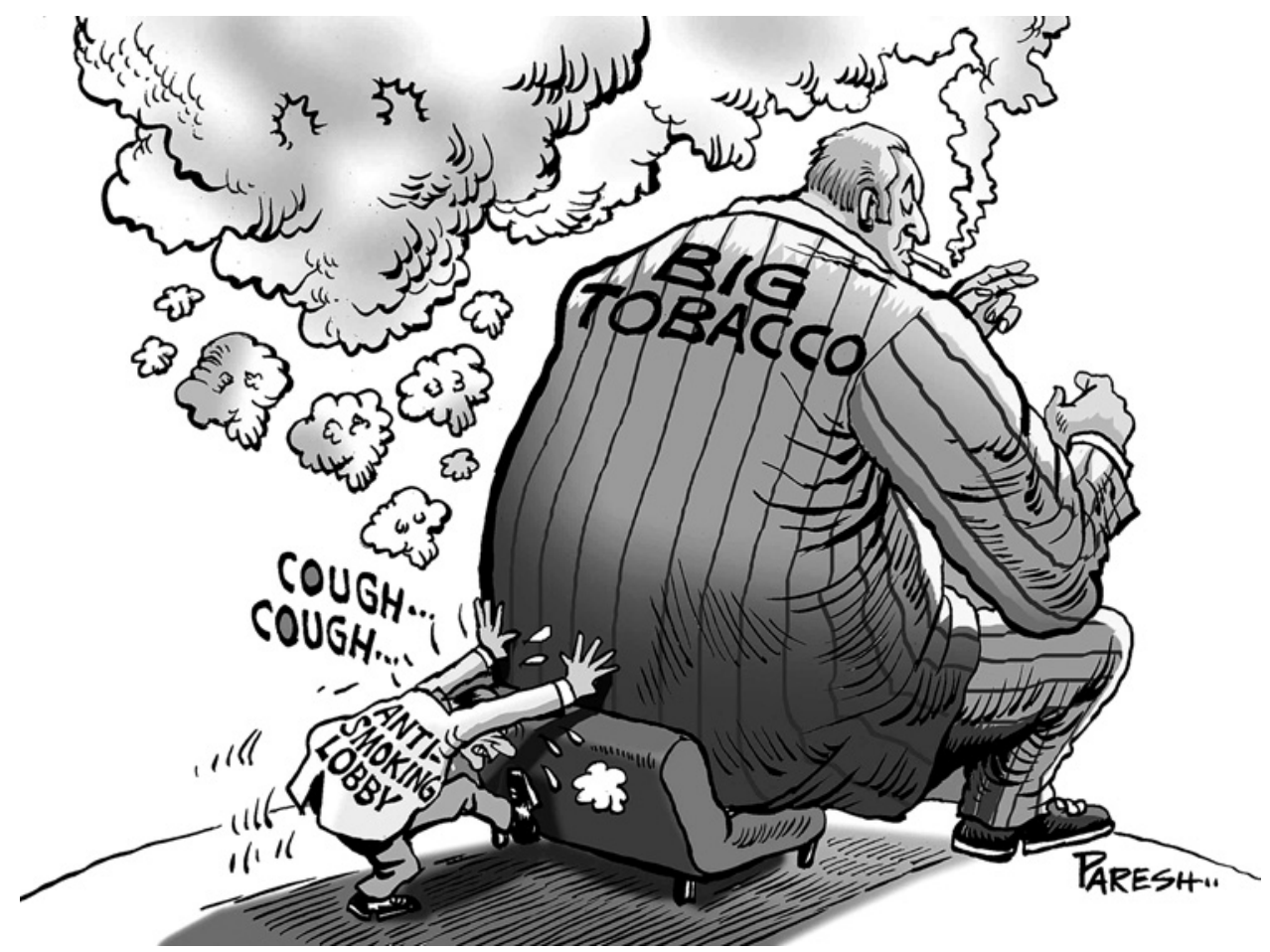

